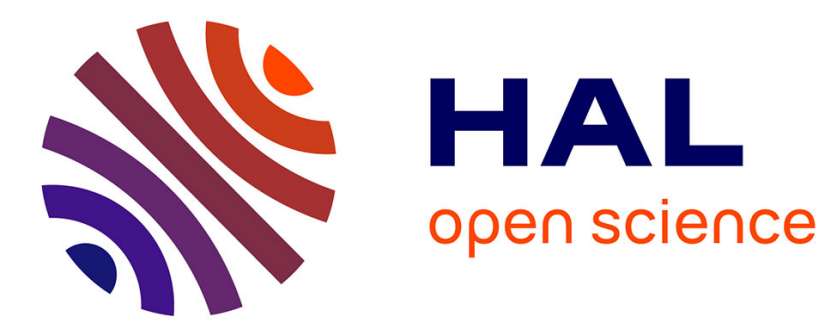

\title{
Knee replacement incidence and social deprivation: results from a French ecological study
}

Murielle Michel, Joséphine Bryere, Milka Maravic, Christian Marcelli

\section{To cite this version:}

Murielle Michel, Joséphine Bryere, Milka Maravic, Christian Marcelli. Knee replacement incidence and social deprivation: results from a French ecological study. Joint Bone Spine, 2019, 10.1016/j.jbspin.2019.03.004 . inserm-02124538

\section{HAL Id: inserm-02124538 https://www.hal.inserm.fr/inserm-02124538}

Submitted on 21 Dec 2021

HAL is a multi-disciplinary open access archive for the deposit and dissemination of scientific research documents, whether they are published or not. The documents may come from teaching and research institutions in France or abroad, or from public or private research centers.
L'archive ouverte pluridisciplinaire HAL, est destinée au dépôt et à la diffusion de documents scientifiques de niveau recherche, publiés ou non, émanant des établissements d'enseignement et de recherche français ou étrangers, des laboratoires publics ou privés.

\section{(ㄷ)(1) $\$$}

Distributed under a Creative Commons Attribution - NonCommerciall 4.0 International 


\section{Knee replacement incidence and social deprivation: results from a French ecological} study

Murielle Michel ${ }^{a, b}$, Joséphine Bryère ${ }^{c}$, Milka Maravic ${ }^{d, e}$ Christian Marcelli MD ${ }^{a, b}$

(a) University Hospital Centre of Caen, Department of Rheumatology, Caen, F-14000, France

(b) University of Caen Normandie, Medical School, Caen, F-14000, France

(c) INSERM, University of Caen Research U1086 ANTICIPE, Caen, F-14076, France

(d) University Hospital Centre of Lariboisière, Department of Rheumatology, Paris, F75475 France

(e) IQVIA, Real World Insights, La Défense Cedex, F-92099, France

Corresponding author: Christian Marcelli

Address: Department of Rheumatology, CHU, avenue de la Côte de Nacre, 14033 Caen cedex 9, France

Tel: (33) 0619545466

Email: marcelli-c@chu-caen.fr 


\begin{abstract}
Objectives: Temporal and geographic variations in knee osteoarthritis (OA) incidence occur worldwide. Regional variations also exist for socioeconomic status. We analyzed the association between socioeconomic deprivation (SED) and knee replacement (KR) incidence and assessed the proportion of KR associated with affluence.

Methods: Patients aged 15 years and over hospitalized for KR in 2013 were included. We linked each patient to a municipality of residence. Municipalities were matched to the 2011 European Deprivation Index score for SED analysis. Poisson regression was performed to examine the association between KR incidence and EDI adjusted for age and sex. The Population Attributable Fraction (PAF) was measured to calculate the proportion of excess of $\mathrm{KR}$ associated with social affluence.
\end{abstract}

Results: We included 77597 KR. KR incidence decreased with increasing SED index. The EDI was significantly associated with $K R$ incidence $(p<0.0001)$. The risk of $K R$ is 2.36 times higher for persons living in the most affluent area compared to those living in the most underprivileged area. The PAF was $28.3 \%$.

Conclusions: The French administrative municipalities with the highest SED have the lowest age- and sex-adjusted KR incidence. It cannot be excluded that patients living in more privileged areas are overtreated. Complementary studies are necessary to define all the individual factors that limit or increase the access to knee replacement.

\title{
Keywords
}

Knee osteoarthritis, knee replacement, social deprivation, European Deprivation Index 


\section{Introduction}

The knee is the joint most frequently affected by osteoarthritis [1]. Guillemin et al. assessed the prevalence of knee OA in France from 2007 to 2009 [1]. About 2.1 to $10 \%$ of men and 1.6 to $14.9 \%$ of women aged 40 to 75 years old were affected. Many consequences such as chronic pain, disability, and negative alterations in quality of life are associated with knee OA [2]. Knee arthroplasty, also known as knee replacement (KR), constitutes a significant development in the management of patients with advanced arthritis of the knee for which conservative medical therapy has failed. KR results in improved pain symptoms and handicap, and therefore, is one of the most commonly performed orthopedic procedures [3]. Annually, about one million KR are performed in the world [3].

Previous studies have shown a temporal variation in knee $O A$ and $K R$ worldwide. For instance, using total knee replacement $(K R)$ as a surrogate marker of severe knee OA, Culliford et al. estimated the lifetime risk of KR in the United Kingdom to range from 8 to $11 \%$ for 50-70 year-old women and from 6 to $8 \%$ for men in the same age group [4]. From 1991 to 2006, the lifetime risk increased by $6.9 \%$ for women and $4.4 \%$ for men [4]. Many risk factors for $\mathrm{KR}$ in persons with knee $\mathrm{OA}$ have been identified in the literature, such as obesity, increased body mass index, radiographic findings including joint space narrowing and MRI detected bone marrow lesions, synovitis and effusion [5-7].

Moreover, a geographic heterogeneity was observed in knee OA prevalence, with a decreasing North-East to South-West gradient in France [1]. Observations are similar in other European countries, with a higher prevalence reported in northern countries, although different methods and OA definitions were used [8]. Reasons for these geographic and temporal variations are not well known. In order to find some explanations, it may be helpful to study various knee OA risk factors. 
Many risk factors for knee OA have been identified in the literature, such as gender, obesity, knee injuries, repetitive joint movement, reduced bone density, muscle weakness, knee malalignment, heavy physical labor, less formal education, and low income [8-14]. Although some of these factors are linked to socioeconomic status (SES), the relationship between the incidence of knee OA and SES appears to be discussed [9-11]. Usually, the SES is analyzed by means of one sole or only a few variables such as racial category, income level, education level, or occupation $[15,16]$. Recently, a European transnational ecological deprivation index, the European Deprivation Index (EDI) [17], was constructed to analyze regional social health inequalities [18]. Deprivation is recognized as being a composite concept, where no single variable can be said to measure it, but rather a number of variables contribute in some way[19].

The aim of our study was two-fold: to analyze the association between KR incidence and EDI as well as to assess the proportion of cases of KR associated with affluence.

\section{Methods}

\subsection{Population study}

In this cross-sectional study, KR data were obtained from the French Hospital National Database which included all hospitalizations occurring in public and private acute care settings in 2013. The validity of this database has previously been shown [19] [20]. We selected all hospital stays related to disease-related groups (DRG) for a first knee prosthesis $(08 \mathrm{C} 241,08 \mathrm{C} 242,08 \mathrm{C} 243,08 \mathrm{C} 244)$ related to knee OA encoded as the primary diagnosis (i.e. ICD-10 code M17) in persons aged 15 years and over ( $n=86$ 052). We only retained the first surgery in the case of a knee prosthesis occurring in the contralateral knee $(n=1531$ patients undergoing contralateral surgery in the same year). Among them, we excluded all hospitalizations for patients not living in metropolitan France or with a wrong postal code because of an error in the transcription of the code in the database (Figure 1). Age, sex, and place of residence (i.e. postal code) were known for every patient. The postal code was used 
to link patients to their municipalities. The EDI was available for municipalities. In most cases, the postal code corresponds to a single municipality, but for some postal codes in rural areas one postal code corresponds to several municipalities, making it impossible to match the postal code to the EDI score. These postal codes were excluded from the analysis. The final selection included $77597 \mathrm{KR}(90.2 \%$ of the initial selection). The study area included 36849 municipalities with a mean of 1100 inhabitants and a standard deviation of 4735 . The French population data used to calculate the KR incidence were those published in 2013 by the National Institute for Statistics and Economic Studies (INSEE).

\subsection{Socioeconomic Deprivation (SED)}

For SED analysis, we used the recently published French version of the EDI [19, 20, 21]. The methodology of EDI was to select ecological census variables that are closely related to individual deprivation using the European Statistics on Income and Living Conditions study. The score of the French EDI (2007) for a geographical unit was calculated using the following formula:

$\mathrm{EDI}=0.24$ * "overcrowding" + 0.66 * "no shower or bathtub" + 0.31 * "foreign" +0.59 * "no car"+ 1.14 * "no high level of education" + 1.13 * "single-parent families" + 0.97 * "families of more than 6 people" + 1.09 * "unemployed" + 1.08 * "non-homeowners".

In this study, we used the EDI score associated with each of the French administrative municipalities. A categorical version of EDI divided into quintiles was used. Quintile 5 corresponds to the most deprived municipalities and quintile 1 corresponds to the least deprived districts.

\subsection{Statistical Analysis}

We compiled the hospitalizations stratified by sex, age group $(<45,45-59,60-74,75-$ $89,>90)$, and place of residence. We calculated the incidence by dividing the number of patients with a KR by the French population for sex, age group, and place of residence. 
Poisson regression was used to examine the association between $\mathrm{KR}$ incidence and SED through the French EDI score in quintiles in a multivariate model including all of the covariates. Quintile 5 was considered as the reference category. Other covariates included age, sex (male sex has been taken as a reference), and the age group $<45$ years. Sex, age group, and their interaction, and categorical EDI were tested. Significance was assigned when the $p$-value was $\leq 0.05$. The natural logarithm of the population size in each municipality was included in the model as the offset because the rates were analyzed instead of counts.

To measure the proportion of cases of KR associated with SED, we assessed the Population Attributable Fraction (PAF) [22]. PAF can be defined as the proportional reduction in average risk over a specified time interval that would be achieved by eliminating the exposure of interest from the population. The PAF is a powerful and validated tool to assess the proportion of cases directly related to the exposure on interest. In our study, the PAF allowed to estimate the excess number of KR associated with the social environment.

The calculation of the PAF needs the relative risks determined for each social deprivation obtained with the previous model. The associated proportion of risk was defined as:

$$
P A F=1-\frac{1}{\sum_{i=1}^{5} p_{i} R R_{i}}
$$

where $p i$ is the proportion of the population at the social deprivation level $i$ and $R R i$ is the relative risk associated with the social deprivation level $I$. The modeling was performed using SAS version 9.3.

\subsection{Role of the funding sources}

All authors were independent from funders and sponsors. Any funder had a role in study design, data collection, data analysis, data interpretation, or writing of the report. The 
corresponding author had full access to all the data in the study and had final responsibility for the decision to submit for publication.

\section{Results}

In 2013, 86052 KR were reported in France of which 77597 were included in this study (Figure 1). Among them, 29599 (38\%) KR were in men and 47998 (62\%) were in women. Over $87 \%$ of KR were in patients at least 60 years of age, among which 42215 (62\%) were women (Table 1).

Table 2 and Figure 2 illustrate the relationship between KR incidence and French EDI in the whole population. Incidence of $K R$ increased as the social deprivation index decreased.

The results of the Poisson regression are given in Table 2. The interaction of age group and sex was not significant and the EDI in quintiles was significantly associated with the incidence of $\mathrm{KR}(p<0.0001)$. Residents of more affluent areas were more likely to have knee replacement than those in less affluent areas. The risk of $K R$ is 2.36 times higher for those living in the most affluent area compared to those living in the most underprivileged area. The analysis of the PAF showed that the participation of the social gradient in KR cases in 2013 is $28.3 \%$. Excess cases associated with social affluence in men and women were calculated at 22 007, whereas expected cases were calculated at 55590 .

\section{Discussion}

This study provides evidence of social disparities in $\mathrm{KR}$ incidence in France. We observed that $\mathrm{KR}$ risk is more than 2 times higher in the least deprived than in the most deprived geographic areas. The analysis of the PAF showed that KR cases were $28.3 \%$ higher in affluent areas.

Relationships between SES and KR incidence have been assessed in previous studies [11, 16]. In a Swedish regional study, Wetterholm et al. evaluated the effect of 
individually-defined SES on the rate of knee and hip replacement due to OA [16]. They found a statistically significant lower hazard ratio for $\mathrm{KR}$ in the lowest income quartile compared to the middle and high quartiles. However, no statistically significant differences remained adjusting for occupation and level of education. Bohensky et al. assessed the link between SES and KR incidence in an Australian population using community indicators of SES [11]. Each patient's area of residence was linked to an index score of SES based on characteristics of economic resources. KR incidence was lower in the low SES tertile group compared to the middle and high SES groups.

Ecological deprivation indices are one of the numerous approaches for measuring SES. They have essentially been developed pragmatically from census data which include a number of variables reflecting the socioeconomic position of the surrounding population. The French EDI is the French version of the European adaptable transnational index. Previous studies using the French EDI have provided evidence of social disparities in the incidence of cancer and osteoporotic hip fracture in France [20, 23].

The association between obesity and knee OA has been well documented [24-26]. Being overweight or obese increases the risk of knee $O A$ and this occurs on a doseresponse gradient of increasing BMI. Consequently, body weight is one of the most important KR risk factors $[13,14]$. A strong relationship between a low SES and overweight or obesity has also been described [27, 28]. This relationship is explained by the low financial resources or greater stress associated with low SES that promotes unhealthy diet and lifestyle [29].

Because we did not have data on BMI, we could not include BMI as a covariate. However, the relationship between KR incidence and SES found in our study contradicts the relationship between body weight and SES described in the literature, which suggests that other factors play an important role in the relationship between KR incidence and SES. 
Physical activities, particularly those which lead to excessive lower extremity joint loading, are important risk factors for knee $\mathrm{OA}$ and $\mathrm{KR}[30,31]$. According to previous studies, socioeconomic inequalities are found in physical activity. One review showed that, among people with low SES, leisure-time physical activity is less prevalent and occupational physical activity is more prevalent. No socioeconomic difference was found in total physical activity [32, 33]. Taken together, these data suggest a complex relationship among SES, physical activity, weight, and risk of knee OA. Such a relationship must be studied including all these factors.

Differences also exist in access to healthcare centers and in willingness to undergo a $\mathrm{KR}$ in patients with $\mathrm{OA}$, but data are conflicting. Rahman et al. quantified the effect of SES on surgical consultation and on total hip and KR rates among 34420 British patients with OA from 1996 to 2004 [34]. Patients with higher SES were more likely to consult an orthopaedic surgeon and underwent more total joint replacements than those with the lowest SES. Cleveland et al. explored the relationship between pain, function, and stiffness outcomes with individual and community SES in 782 patients with radiographic knee OA [35]. Community SES was based on the community poverty rate, defined as the percentage of households falling below the Census Bureau measure of poverty line. Individual SES was defined by educational level and occupation. Lower individual and community SES were associated with worse function and pain outcomes [35]. More recently, Feldman et al. found similar results in a cohort of 316 patients with scheduled KR [36]. Individual SES was defined by education level, while community SES was defined using a composite index including neighbourhood factors such as social cohesion, social capital, and neighbourhood safety. Pollard et al. found a lower level of impairment in less deprived patients with hip and knee radiographic OA [37]. Social deprivation was defined by the Townsend index, based on the four variables from the 1991 census: unemployment, non car-ownership, non home-ownership, and household overcrowding. 
Another explanation for the link found between SES and KR incidence is the difference in patient travel distance to the hospital and access to care in relation to SES. In France, the most privileged populations live near the center of a big city, where the density of medical facilities is higher, whereas the most deprived persons live further away in the suburbs or in rural towns. Geographic remoteness from hospitals could be a barrier to access to specialized surgeons as has already been described for cancer [38]. Moreover, in France, most surgeons working in private acute care charge additional fees that could limit the willingness to undergo a KR in the poorest patients.

Our study had several methodological strengths. First, the study included a large sample size with nearly complete French data for the year. To our knowledge, it is the first national ecological study analyzing the association between socioeconomic deprivation and knee replacement incidence. Second, the EDI used is a new index with external validity and utility across time and space. Third, knowing the sociodemographic distribution of KR with an increased incidence in women and older persons, we have adjusted KR incidence for sex and age.

Our study presents some limitations. First, we used the local municipality as a geographic unit. However, some municipalities do not have their own municipality code. Therefore, these municipalities were excluded from the analysis. As these municipalities are mainly located in rural areas with similar SES profiles, we cannot rule out the hypothesis that exclusion of these municipalities has influenced our results. Indeed, the rural French population being rather disadvantaged, the exclusion of a part of this population probably favoured our demonstration. However, the most deprived individuals live in the suburbs, assuring us that they were included in our analysis. On the other hand, some large towns in France have several postal codes. In these towns, the analysis included the districts defined by the postal codes. Second, using an ecological index introduced an ecological bias into the measurement of individual SES. We do not have individual data, and it may appear that persons living in the same area have the same deprivation level, which may not always be 
true. An ecological index also limits the distinction between a true neighborhood effect and individual social deprivation correlated with neighborhood characteristics. The higher KR incidence in advantaged areas can be due to the higher proportion of advantaged individuals in these areas (composition effect) or it can be due to other aspects specific to the areas associated with $\mathrm{KR}$ risk (context effect). Moreover, we relied on the postal code at the time of data collection to measure environment, without taking into account the personal history of individuals in terms of geographical or social mobility. Therefore, the data source from the French Hospital Database could not ensure the completeness of the data. Third, we considered that all $\mathrm{KR}$ are due to $\mathrm{OA}$ while it affects only $95 \%$ of $\mathrm{KR}$ according to epidemiology.

The assumptions that can be raised are that increased body weight, level of physical activity, or impact of knee OA felt by the patient could be the factors explaining the variations in KR incidence. However, this could not be analyzed because administrative data, does not allow for adjustments.

Finally, our study showed that the French administrative municipalities with the highest socioeconomic deprivation have the lowest age- and sex-adjusted knee replacement incidence. The risk of knee replacement results from the risk of knee osteoarthritis combined with many factors influencing the probability of receiving a knee replacement or not, such as willingness to undergo a surgery and access to care. Some of these factors are strongly influenced by the characteristics of the national health system. Moreover, it cannot be excluded that patients living in more privileged areas are overtreated. Therefore, complementary studies are necessary to define all the individual factors that limit or increase the access to knee replacement in France.

\section{Conflict of interest}


Murielle Michel, Josephine Bryère, and Milka Maravic have no conflict of interest to report related to this manuscript.

Christian Marcelli has received research grants and/or travel reimbursements from Amgen, MSD, Lilly, and Novartis. 


\section{References}

1. Guillemin F, Rat AC, Mazieres B, et al. Prevalence of symptomatic hip and knee osteoarthritis: a two-phase population-based survey. Osteoarthritis Cartilage. 2011;19:131422.

2. Vos T, Allen C, Arora M, et al. Global, regional, and national incidence, prevalence, and years lived with disability for 310 diseases and injuries, 1990-2015: a systematic analysis for the Global Burden of Disease Study 2015. Lancet. 2016;388:1545-602.

3. Kurtz SM, Lau E, Ong K, Zhao K, Kelly M, Bozic KJ. Future young patient demand for primary and revision joint replacement: national projections from 2010 to 2030. Clin Orthop Relat Res. 2009;467:2606-12.

4. Culliford DJ, Maskell J, Kiran A, et al. The lifetime risk of total hip and knee arthroplasty: results from the UK general practice research database. Osteoarthritis and cartilage. 2012;20:519-24.

5. Nielsen FK, Egund N, Jorgensen A, Jurik AG. Risk factors for joint replacement in knee osteoarthritis; a 15-year follow-up study. BMC musculoskeletal disorders. 2017;18:510.

6. Reyes C, Leyland KM, Peat G, Cooper C, Arden NK, Prieto-Alhambra D. Association Between Overweight and Obesity and Risk of Clinically Diagnosed Knee, Hip, and Hand Osteoarthritis: A Population-Based Cohort Study. Arthritis \& rheumatology. 2016;68:1869-75.

7. Leyland KM, Judge A, Javaid MK, et al. Obesity and the Relative Risk of Knee Replacement Surgery in Patients With Knee Osteoarthritis: A Prospective Cohort Study. Arthritis \& rheumatology. 2016;68:817-25.

8. Quintana JM, Arostegui I, Escobar A, Azkarate J, Goenaga JI, Lafuente I. Prevalence of knee and hip osteoarthritis and the appropriateness of joint replacement in an older population. Arch Intern Med. 2008;168:1576-84. 
9. Bann D, Johnson W, Li L, Kuh D, Hardy R. Socioeconomic Inequalities in Body Mass Index across Adulthood: Coordinated Analyses of Individual Participant Data from Three British Birth Cohort Studies Initiated in 1946, 1958 and 1970. PLoS Med. 2017;14:e1002214.

10. Vulcano E, Memtsoudis S, Della Valle AG. Bilateral total knee arthroplasty guidelines: are we there yet? The journal of knee surgery. 2013;26:273-9.

11. Bohensky MA, Ackerman I, DeSteiger R, Gorelik A, Brand CA. Lifetime risk of total knee replacement and temporal trends in incidence by health care setting, socioeconomic status, and geographic location. Arthritis care \& research. 2014;66:424-31.

12. Zhang Y, Jordan JM. Epidemiology of osteoarthritis. Clinics in geriatric medicine. 2010;26:355-69.

13. Blagojevic M, Jinks C, Jeffery A, Jordan KP. Risk factors for onset of osteoarthritis of the knee in older adults: a systematic review and meta-analysis. Osteoarthritis and cartilage. 2010;18:24-33.

14. Silverwood V, Blagojevic-Bucknall M, Jinks C, Jordan JL, Protheroe J, Jordan KP. Current evidence on risk factors for knee osteoarthritis in older adults: a systematic review and meta-analysis. Osteoarthritis and cartilage. 2015;23:507-15.

15. Hawkins K, Escoto KH, Ozminkowski RJ, Bhattarai GR, Migliori RJ, Yeh CS. Disparities in major joint replacement surgery among adults with Medicare supplement insurance. Population health management. 2011;14:231-8.

16. Wetterholm M, Turkiewicz A, Stigmar K, Hubertsson J, Englund M. The rate of joint replacement in osteoarthritis depends on the patient's socioeconomic status. Acta orthopaedica. 2016;87:245-51. 
17. Pornet C, Delpierre C, Dejardin O, et al. Construction of an adaptable European transnational ecological deprivation index: the French version. Journal of epidemiology and community health. 2012;66:982-9.

18. Folwell K. Single measures of deprivation. Journal of epidemiology and community health. 1995;49 Suppl 2:S51-6.

19. Maravic M, Landais P. Usefulness of a national hospital database to evaluate the burden of primary joint replacement for coxarthrosis and gonarthrosis in patients aged over 40 years. Osteoarthritis and cartilage. 2006;14:612-5.

20. Petit M, Bryere J, Maravic M, Pallaro F, Marcelli C. Hip fracture incidence and social deprivation: results from a French ecological study. Osteoporosis international : a journal established as result of cooperation between the European Foundation for Osteoporosis and the National Osteoporosis Foundation of the USA. 2017.

21. Guillaume E, Pornet C, Dejardin O, et al. Development of a cross-cultural deprivation index in five European countries. Journal of epidemiology and community health. $2016 ; 70: 493-9$.

22. Rockhill B, Newman B, Weinberg C. Use and misuse of population attributable fractions. American journal of public health. 1998;88:15-9.

23. Bryere J, Dejardin O, Bouvier V, et al. Socioeconomic environment and cancer incidence: a French population-based study in Normandy. BMC cancer. 2014;14:87.

24. Lee R, Kean WF. Obesity and knee osteoarthritis. Inflammopharmacology. 2012;20:53-8.

25. Deshpande BR, Katz JN, Solomon DH, et al. Number of Persons With Symptomatic Knee Osteoarthritis in the US: Impact of Race and Ethnicity, Age, Sex, and Obesity. Arthritis care \& research. 2016;68:1743-50. 
26. Vasilic-Brasnjevic S, Marinkovic J, Vlajinac $\mathrm{H}$, et al. Association of body mass index and waist circumference with severity of knee osteoarthritis. Acta reumatologica portuguesa. 2016;41:226-31.

27. Sobal J, Stunkard AJ. Socioeconomic status and obesity: a review of the literature. Psychological bulletin. 1989;105:260-75.

28. Vernay M, Malon A, Oleko A, et al. Association of socioeconomic status with overall overweight and central obesity in men and women: the French Nutrition and Health Survey 2006. BMC public health. 2009;9:215.

29. Cheon BK, Hong YY. Mere experience of low subjective socioeconomic status stimulates appetite and food intake. Proceedings of the National Academy of Sciences of the United States of America. 2017;114:72-7.

30. Allen KD, Golightly YM. State of the evidence. Current opinion in rheumatology. 2015;27:276-83.

31. Johnsen MB, Hellevik Al, Baste V, et al. Leisure time physical activity and the risk of hip or knee replacement due to primary osteoarthritis: a population based cohort study (The HUNT Study). BMC musculoskeletal disorders. 2016;17:86.

32. Beenackers MA, Kamphuis $\mathrm{CB}$, Giskes $\mathrm{K}$, et al. Socioeconomic inequalities in occupational, leisure-time, and transport related physical activity among European adults: a systematic review. The international journal of behavioral nutrition and physical activity. 2012;9:116.

33. Bell JA, Hamer M, Batty GD, Singh-Manoux A, Sabia S, Kivimaki M. Combined effect of physical activity and leisure time sitting on long-term risk of incident obesity and metabolic risk factor clustering. Diabetologia. 2014;57:2048-56. 
34. Rahman MM, Kopec JA, Sayre EC, et al. Effect of sociodemographic factors on surgical consultations and hip or knee replacements among patients with osteoarthritis in British Columbia, Canada. The Journal of rheumatology. 2011;38:503-9.

35. Cleveland RJ, Luong ML, Knight JB, et al. Independent associations of socioeconomic factors with disability and pain in adults with knee osteoarthritis. BMC musculoskeletal disorders. 2013;14:297.

36. Feldman $\mathrm{CH}$, Dong $\mathrm{Y}$, Katz JN, Donnell-Fink LA, Losina E. Association between socioeconomic status and pain, function and pain catastrophizing at presentation for total knee arthroplasty. BMC musculoskeletal disorders. 2015;16:18.

37. Pollard B, Dixon D, Johnston M. Does the impact of osteoarthritis vary by age, gender and social deprivation? A community study using the International Classification of Functioning, Disability and Health. Disability and rehabilitation. 2014;36:1445-51.

38. Gentil J, Dabakuyo TS, Ouedraogo S, Poillot ML, Dejardin O, Arveux P. For patients with breast cancer, geographic and social disparities are independent determinants of access to specialized surgeons. A eleven-year population-based multilevel analysis. BMC cancer. 2012;12:351. 


\section{FIGURE LEGENDS}

Figure 1: Flowchart of inclusion procedure (EDI: European Deprivation Index)

Figure 2: Total knee replacement incidence ( $n$ per 100,000 inhabitants) in France in 2013 according to quintiles of European Deprivation Index in both sexes (crude incidence, not adjusted for age). EDI quintile 1 corresponds to the least deprived municipalities, and quintile 5 to the most deprived municipalities. 
Figure 1: Flowchart of inclusion procedure (EDI: European Deprivation Index)

\section{Exelusion of hospitalizations for}

- Patients not living in metropolitan

\section{France}

- With a wrong postal code due to transeription efror of the code in the database

- Code corresponded to sweral municipalities.

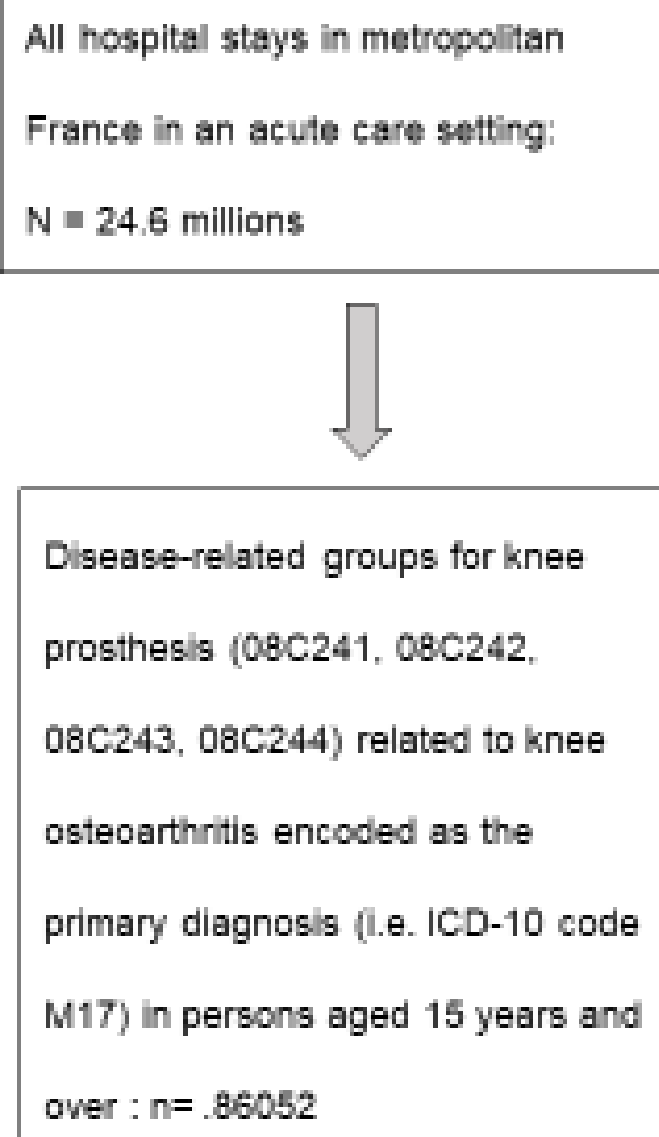


Figure 2: Total knee replacement incidence in France in 2013 according to quintiles of European Deprivation Index.

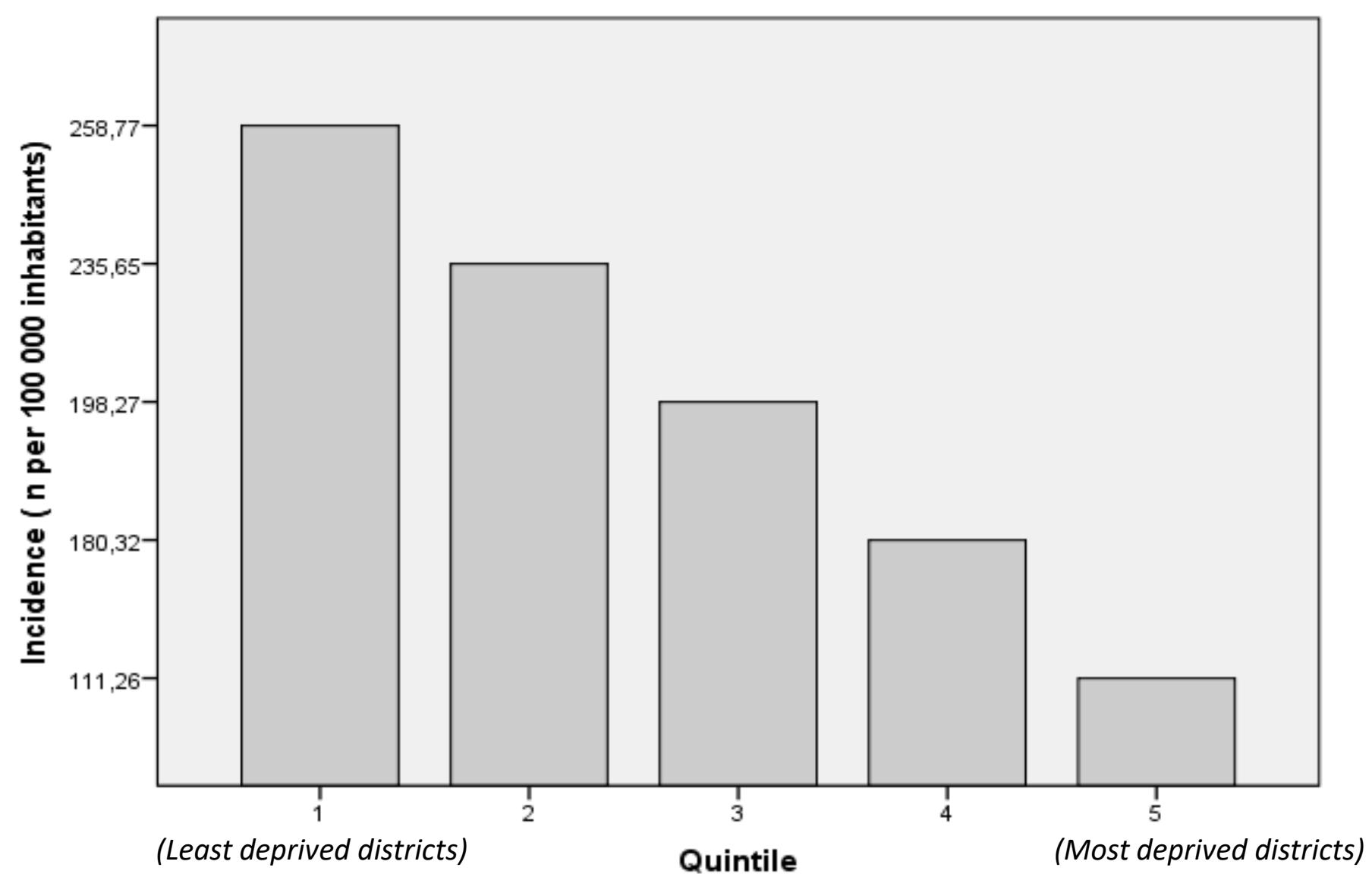


Table 1: Number and percentage of knee replacements in the French metropolitan population in 2013 according to sex and age.

\begin{tabular}{llll}
\hline \multirow{2}{*}{ Age range, years } & \multicolumn{3}{c}{ Sex } \\
\cline { 2 - 4 } & Total, $\mathrm{n}=77597$ & Men, $\mathrm{n}=29599(38.2)$ & Women, $\mathrm{n}=47998(62.8)$ \\
\hline$<45, \mathrm{~N}(\%)$ & $428(0.5)$ & $210(0.7)$ & $218(0.4)$ \\
$45-59, \mathrm{~N}(\%)$ & $9491(12.2)$ & $3926(13.2)$ & $5565(11.6)$ \\
$60-74, \mathrm{~N}(\%)$ & $39615(51.0)$ & $15806(53.4)$ & $23809(49.6)$ \\
$75-89, \mathrm{~N}(\%)$ & $27730(35.7)$ & $9572(32.3)$ & $18158(37.8)$ \\
$\geq 90, \mathrm{~N}(\%)$ & $333(0.4)$ & $85(0.3)$ & $248(0.5)$ \\
Total, N (\%) & $77597(100)$ & $29599(100)$ & $47998(100)$ \\
\hline
\end{tabular}

Data are expressed as number (percentage) 
Table 2: Results of Poisson regression between the categorical version of the European Deprivation Index and knee replacement incidence adjusted to sex and age

\begin{tabular}{|c|l|l|l|l|}
\hline Variables & $\mathbf{N}$ & Estimation & $95 \% \mathbf{C l}$ & p-value \\
\hline Sex & & & & \\
\hline Male & 29599 & 1 & & \\
\hline Female & 47998 & 1.34 & 1.29 to 1.38 & $<0.0001$ \\
\hline Age class & & & & \\
(years) & & & & \\
\hline$<45$ & 428 & 1 & 266.45 to 432.16 & $<0.0001$ \\
\hline $45-59$ & 9491 & 59.42 & 336.57 to 546.48 & $<0.0001$ \\
\hline 60-74 & 39615 & 339.34 & 29.35 to 62.06 & $<0.0001$ \\
\hline $75-89$ & 27730 & 428.85 & 1.55 to 1.72 & $<0.0001$ \\
\hline$\geq 90$ & 333 & 42.68 & & $<0.0001$ \\
\hline Qutegorical \\
EDI
\end{tabular}

95\% Cl, 95\% confidence interval; EDI, European Deprivation Index 